\title{
Analysis of Land Surface Energy and Water Cycle Changes in Naqu Region of Qinghai-Tibet Plateau during 2005-2016
}

\author{
Hao Wang, Jie Ma* \\ School of Atmospheric Sciences, Chengdu University of Information Technology, Chengdu, China \\ Email: 576545063@qq.com, ${ }^{\star} 961393820 @ q q . c o m$
}

How to cite this paper: Wang, H. and Ma, J. (2021) Analysis of Land Surface Energy and Water Cycle Changes in Naqu Region of Qinghai-Tibet Plateau during 2005-2016. Open Access Library Journal, 8: e7670. https://doi.org/10.4236/oalib.1107670

Received: June 21, 2021

Accepted: July 20, 2021

Published: July 23, 2021

Copyright $\odot 2021$ by author(s) and Open Access Library Inc.

This work is licensed under the Creative Commons Attribution International License (CC BY 4.0).

http://creativecommons.org/licenses/by/4.0/

\section{(c) (i) Open Access}

\begin{abstract}
In order to improve the integrity of the research on the thermal conditions of the Qinghai-Tibet Plateau and the plateau energy cycle, and strengthen the understanding of the climate change and water cycle in the Nagqu area, this article uses the 2005-provided by the Naqu Alpine Climate and Environmental Observation and Research Station of the Northwest Institute of EcoEnvironmental Resources, Chinese Academy of Sciences. In 2016, the hour by hour high-resolution data set of atmospheric, soil and eddy observations analyzed the surface radiation budget, energy conversion, energy balance, and energy closure in the Naqu region of the Qinghai-Tibet Plateau. The following conclusions are obtained: compared with sunny days, the diurnal variation of the various components of surface energy in Nagqu in cloudy weather is very irregular, and the reflectivity of cloudy weather becomes larger. In cloudy weather, the thermal process between the surface and the atmosphere and deep soil is more violent than short-wave radiation. The albedo at each moment of the day in winter is greater than that in summer because of the unique surface characteristics of the plateau. Both summer and winter sensible heat flux and latent heat flux have the same diurnal variation trend as net radiation. The sensible heat flux and latent heat flux in summer are significantly higher than those in winter, but the latent heat flux changes more significantly with the seasons. When considering the soil heat storage term, the energy closure degree in summer is 0.301 and that in winter is 0.701 . The energy closure degree in winter is significantly higher than that in summer.
\end{abstract}

\section{Subject Areas}

Atmospheric Science 


\section{Keywords}

Qinghai Tibet Plateau, Radiation Budget, Energy Balance, Heat Storage Term, Energy Closure

\section{Introduction}

As the largest plateau in China and the highest in the world, the Qinghai-Tibet Plateau plays an important role in global atmospheric energy cycle and global climate change. Due to its unique high altitude and complex landform, the land surface process and its water cycle of the plateau have an extremely important influence on the climate change and the generation of extreme weather phenomena in China [1]. The Qinghai-Tibet Plateau has a variety of complex underlying surfaces, including snow mountain glaciers, plateau lakes, woodlands, meadows, wetlands and so on. The study of land-air interaction on various underlying surfaces is not only conducive to deepening the understanding of climate and environmental changes in different regions of China, but also conducive to the study of global climate change. Surface energy balance and radiation balance are the main contents of land surface processes and land-air interactions [2], as well as the main links of land surface energy and moisture conversion and circulation. The study of the above process can be said to be the first step in the study of land-air interaction.

Due to the restriction of transportation and environment, most of the previous studies on land surface processes and surface energy were concentrated in the arid region of Northwest China, Loess Plateau and the eastern, southern and northern parts of the Qinghai-Tibet Plateau, but less on the central part of the Plateau. In addition, the underlying surface of previous studies is mostly sparse vegetation, and there are few studies on the areas where the underlying surface is alpine meadow. Naqu area is located in the hinterland of the Qinghai-Tibet Plateau, about $1156 \mathrm{Km}$ from east to west, $760 \mathrm{Km}$ from north to south, $83^{\circ} 55^{\prime}$ to $95^{\circ} 05 \mathrm{E}, 29^{\circ} 55^{\prime}$ to $36^{\circ} 30^{\prime} \mathrm{N}$, with a longitude difference of $11^{\circ} 10^{\prime}$ from east to west, and a latitude difference of $6^{\circ} 35^{\prime}$ from south to north. It is the core area of plateau thermal action.

Under the influence of plateau monsoon, this region has a plateau monsoon climate with abundant rainfall. The underlying surface is representative of the alpine meadow in northern Tibet. Seasonal freeze-thaw exists in soil, and the freeze-thaw process helps to strengthen the energy exchange between ground and air [3]. Therefore, the study of land surface process and energy cycle in this region can not only improve the integrity of the study of thermal condition and energy cycle of the Qinghai-Tibet Plateau, enhance the understanding of climate change and water cycle in this region, but also contribute to the restoration of degraded grassland [4] [5].

Since the study of land-air interaction in the 1950s, the observation and analy- 
sis of surface radiation and energy balance characteristics have become the focus of global change and climate anomaly research, and a series of studies and experiments on land surface processes have been carried out by international scientific community. For example, the Hydrologyat Moshpere Pilot Experiment (HAPEX) [6] and the Northern Hemisphere Climate Change Land Surface Experiment (NOPEX) [7]. In line with the international trend, China has also carried out many comprehensive land surface observation experiments in the past 30 years. The famous ones are Heihe Earth-Atmosphere Interaction Observation Experiment (HEIFE) [8], Inner Mongolia Semi-arid Grassland Soil-Vegetation-Atmosphere Interaction Experiment (IMGRASS) [9], Northwest China Arid Land-Atmosphere Interaction Experiment (NWCALIEX) [10], and the Third Qinghai-Tibet Plateau Atmospheric Science Experiment (TIPEX) [11].

Through the above large-scale field experiments, Chinese researchers have made a series of achievements in the study of land surface and hydrological processes. Such as zhangqiang [12] using qi lu interaction experiment in arid areas of northwest China (NWC-ALIEX) obtained by observation data analysis of the northwest arid and semi arid areas of the essential characteristics of the surface heat balance and radiation balance, hui-zhiliu [13], such as the research results show that in the growing season, the underlying surface in semi-arid area of farmland and grassland area, the energy budget of the near surface layer is basically the same. The sensible heat flux is the main part of the surface energy, and the latent heat flux and the surface heat flux are very small.

However, due to the accuracy of the observations, the accuracy of the models, and the insufficient understanding of the atmospheric and water cycle processes, the future scientific researchers need to strengthen the in-depth discussion of the land surface processes.

\section{Materials and Methods}

\subsection{Introduction of Observation Data}

The data in this study were from the Naqu Observation Field of the Naqu Alpine Climate and Environment Observation and Research Station, Northwest Institute of Eco-Environment and Resources, Chinese Academy of Sciences $\left(31^{\circ} 37^{\prime} \mathrm{N}\right.$, $91^{\circ} 90^{\prime} \mathrm{E}$, altitude $\left.4509 \mathrm{~m}\right)$. The observation site was flat and open, with uneven vegetation with a height of $3-20 \mathrm{~cm}$. The observed data were representative to a certain extent. The data includes hourly atmospheric, soil and eddy observations from 2005 to 2016. However, due to the lack of data measurements and errors in some data, this paper really adopted more accurate and continuous hourly radiation data in 2012 and 2016, as well as atmospheric, soil and eddy observation data. Specifically, it contains the gradient observation data composed of multi-layer wind speed and direction, multi-layer temperature, multi-layer humidity, air pressure and precipitation, as well as the radiation data of four components (downward short-wave radiation, upward short-wave radiation, downward long-wave radiation and upward long-wave radiation). Multilayer $(5 \mathrm{~cm}$, 
$10 \mathrm{~cm}, 20 \mathrm{~cm}, 40 \mathrm{~cm}, 80 \mathrm{~cm}$ ) soil temperature, humidity, soil heat flux observation data and turbulence data composed of sensible heat flux, latent heat flux and carbon dioxide flux. Among them, precipitation, evaporation and $\mathrm{CO}_{2}$ flux data are daily cumulative values, while other observation elements are daily average values.

\subsection{The Research Content}

The interaction between the earth and the atmosphere is mainly realized by the exchange of matter and energy in the way of turbulence, and the surface radiation balance is the energy link of the interaction between the earth and the atmosphere [14]. Therefore, this paper will study the diurnal and seasonal variation characteristics of the four components of near-surface radiation, compare the surface reflectance of Naqu area with other different underlying surfaces, analyze the diurnal and seasonal variation characteristics of the surface energy flux in Naqu area, and grasp the energy exchange mode and law between the surface and atmosphere. It is hoped that this study will help to understand the impact of surface energy budget on climate change in this region. At the same time, large-scale changes in land albedo, roughness and soil moisture content may lead to changes in land-air feedback mechanism [15], which will also be discussed in this paper.

\section{Results Analysis}

\subsection{Analysis of Surface Radiation Budget under Typical Weather Conditions}

There are various forms of energy transfer and conversion between the atmosphere and the ground, but solar radiation is almost the only energy source accepted by the ground. The surface radiation budget includes RSD of solar short-wave radiation reaching the surface through the atmosphere, RSU of short-wave radiation upward reflected from the surface, RLD of atmospheric long-wave radiation downward emitted after the absorption of energy by atmospheric aerosols, and RLU of long-wave radiation upward reflected from the surface. According to these four components, the net radiation energy received by the surface can be calculated as $\mathrm{Rn}=(\mathrm{RSD}-\mathrm{RSU})+(\mathrm{RLD}+\mathrm{RLU})$. Net radiation is positive and net radiation is negative, indicating heat loss. We selected three different typical weather conditions: sunny day, rainy day and cloudy day to analyze the diurnal variation of each component of surface radiation under typical weather conditions. The specific dates are August 25, 2012, July 4, 2012 and August 23, 2012.

As can be seen from Figure 1, in summer 2012, the radiation received by the surface and the radiation emitted upward under various weather conditions in $\mathrm{Na}$ qu area have obvious diurnal variations, and the variation trend is generally consistent. Each radiation component reaches its peak value in one day at about 12:00 noon. The main radiation energy received by the earth's surface is the solar downward shortwave radiation, and the intensity of the solar downward shortwave 


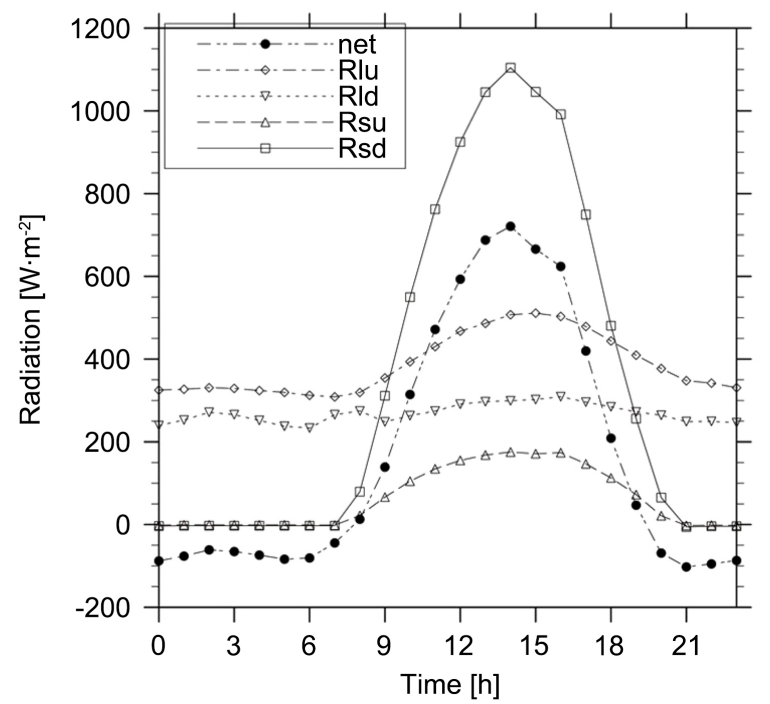

(a)

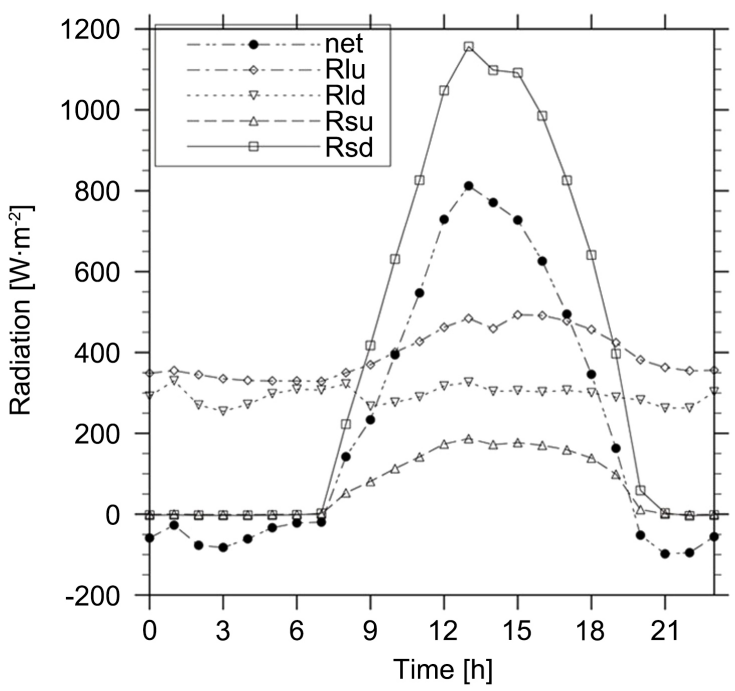

(b)

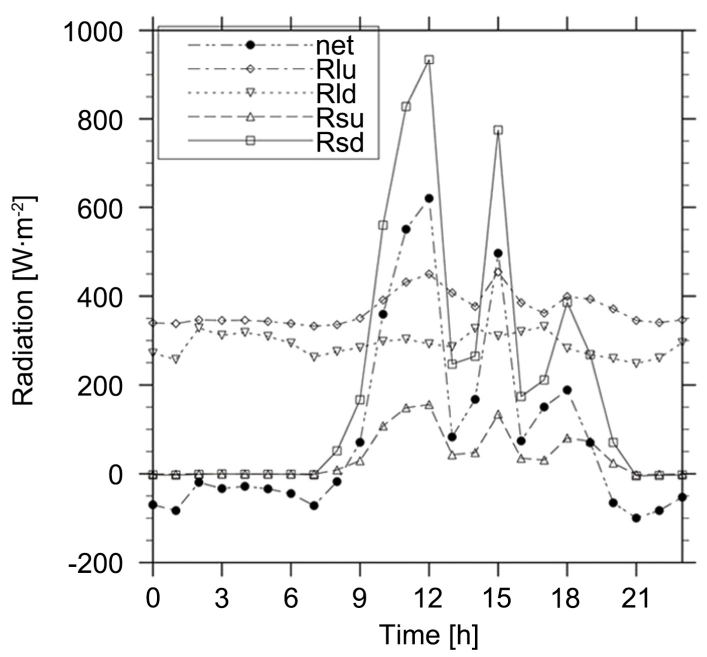

(c)

Figure 1. The diurnal variation of surface radiation in sunny (a); rainy (b); cloudy (c) weather in Naqu region in summer of 2012.

radiation is related to many factors, among which the two most important factors are the solar altitude Angle and atmospheric transparency. The smaller the sun's altitude Angle, the less radiation reaches the surface. Therefore, the variation of the downward shortwave radiation received by the earth's surface during the day is basically the same as the variation of the sun's altitude Angle, reaching the maximum at noon and the minimum in the morning and evening. The peak value of downward shortwave radiation in rainy days is slightly larger than that in sunny days. In rainy afternoons, under the influence of cloud and rain, the solar shortwave radiation reaching the ground is affected, which shows an uneven trend in the figure. Under cloudy weather, under the influence of clouds, the total radiation is obviously reduced, and the change is very uneven. There are multiple peaks throughout the day, but as time goes on, the size of each peak decreases gradually.

The surface reflectance is the ratio of upward shortwave radiation to down- 
ward shortwave radiation, which is 0.22 on rainy days, 0.33 on cloudy days and 0.29 on sunny days. If a typical sunny day is taken as a reference, the cloud cover increases in cloudy days and the scattered radiation increases, leading to the increase of upward shortwave radiation and the increase of reflectance [16] [17]. On rainy days, soil moisture and soil color are significantly greater than (deeper than) on sunny days, so the solar radiation absorbed by the surface becomes more and the surface reflectivity becomes smaller. On sunny days, the upward long-wave radiation also has obvious diurnal variation, but the range of variation is significantly smaller than the downward short-wave radiation, and the peak reaches at 3:00 in the afternoon, which is slightly two hours behind the peak of solar short-wave radiation, because it still takes some time for the surface warming to emit long-wave radiation. The upward long-wave radiation at night is always positive in clear days, indicating that the surface is losing heat at night.

The diurnal variation of the upward long-wave radiation in cloudy days is similar to that of the solar short-wave radiation, but the peak value is significantly smaller than that of the sunny days, indicating that the downward short-wave radiation has a more obvious heating effect on the surface than that of the atmospheric long-wave radiation. The magnitude of downward long-wave radiation is mainly determined by the upward long-wave radiation from the ground [18]. However, in cloudy weather, the atmospheric warming is more obvious due to the influence of cloud amount and cloud state. The daily net radiation integral value in clear days was $47.04 \mathrm{MJ} /\left(\mathrm{m}^{2} \cdot \mathrm{d}\right)$, accounting for $48 \%$ of the total daily radiation integral value. The daily integral value of downward shortwave radiation in cloudy weather is $56.88 \mathrm{MJ} /\left(\mathrm{m}^{2} \cdot \mathrm{d}\right)$, and the daily integral value of net radiation is $24.65 \mathrm{MJ} /\left(\mathrm{m}^{2} \cdot \mathrm{d}\right)$, accounting for $43 \%$. With the increase of cloud cover, the daily integral value of net radiation decreases, and its proportion in the total radiation also decreases, indicating that the variation of thermal process between the surface, atmosphere and deep soil is more intense than that of shortwave radiation under cloudy weather.

\subsection{Analysis of Surface Radiation Balance in Different Seasons}

As shown in Figure 2, the total daily integral values of radiation in July and December were $69.71 \mathrm{MJ} /\left(\mathrm{m}^{2} \cdot \mathrm{d}\right)$ and $43.58 \mathrm{MJ} /\left(\mathrm{m}^{2} \cdot \mathrm{d}\right)$, and the daily integral values of downward shortwave radiation in the curved region on page 7 and 15 in winter and summer were significantly higher than the observed results in the alpine grassland in the source region of the Yellow River [18]. The daily integral value of downward long wave radiation in Naqu area is $89.4 \mathrm{MJ} /\left(\mathrm{m}^{2} \cdot \mathrm{d}\right)$ in summer and $50.4 \mathrm{MJ} /\left(\mathrm{m}^{2} \cdot \mathrm{d}\right)$ in winter. The magnitude of atmospheric downward long-wave radiation is mainly deter-mined by the surface upward long-wave radiation, and is affected by cloud conditions, atmospheric humidity, temperature stratification, etc. In summer, the down-ward long-wave radiation accounted for $83 \%$ of the upward long-wave radiation on the ground, while only $70 \%$ in winter, indicating that the upward long-wave radiation on the ground was more "reflected" by the 


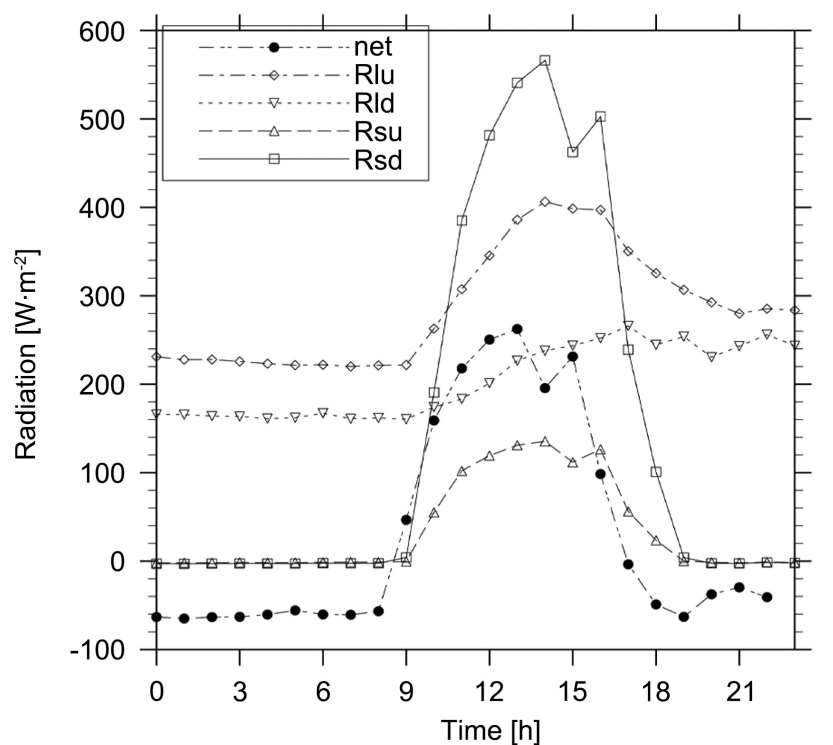

(a)

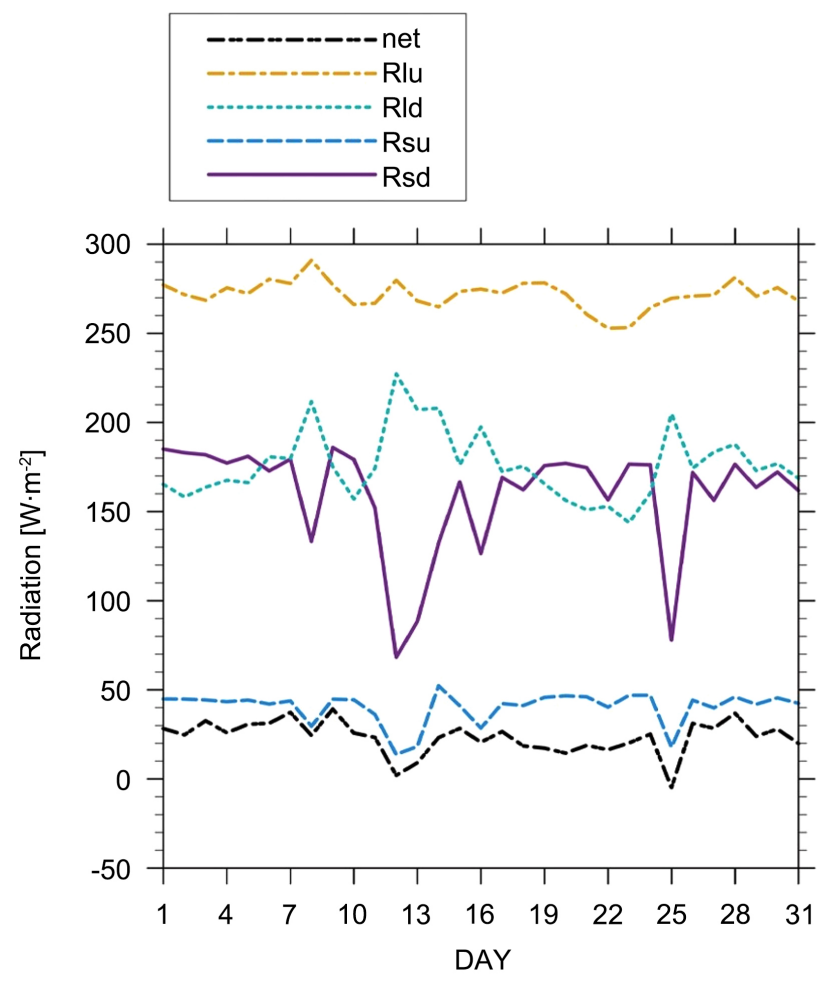

(c)

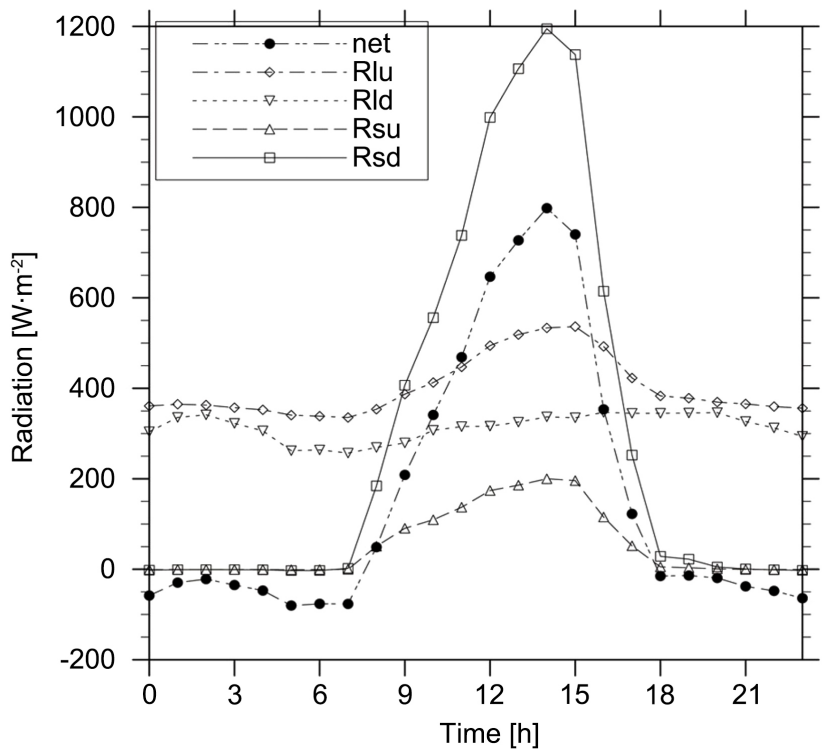

(b)

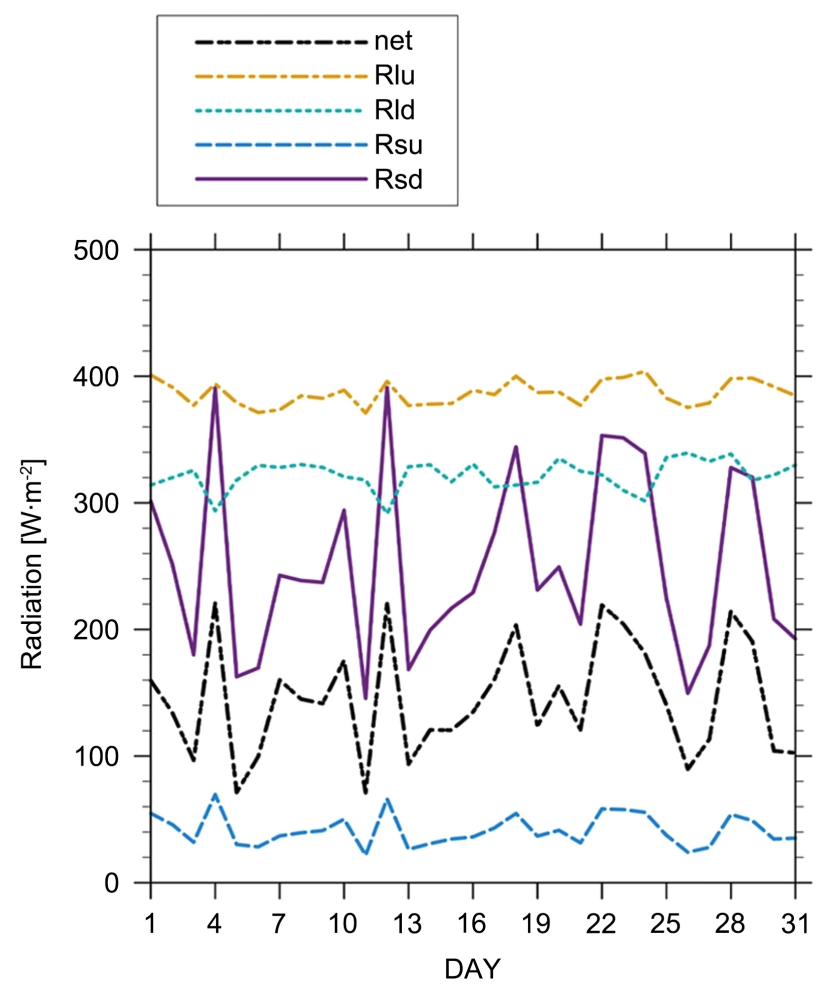

(d)

Figure 2. Changes of radiation components in July and December 2012 in Naqu area. (a) Average diurnal variation of radiation components in December; (b) average diurnal variation of radiation components in July; (c) diurnal variation of radiation components in December; (d) diurnal variations in the radiation components in July.

atmosphere in summer. The reason for this phenomenon is that there are more clouds and rain in summer, and the atmospheric insulation effect is better. The daily integral amounts of upward shortwave radiation in July and December were $11.51 \mathrm{MJ} /\left(\mathrm{m}^{2} \cdot \mathrm{d}\right)$ and $16.32 \mathrm{MJ} /\left(\mathrm{m}^{2} \cdot \mathrm{d}\right)$, which accounted for $16 \%$ and $37 \%$ of 
downward shortwave radiation, respectively.

It was obvious that the reflectance of the underlying surface in Naqu region in winter was higher than that in summer. Surface reflectance is defined as $\alpha=$ RSU/RSD, where RSU refers to the upward short-wave radiation of the surface and RSD refers to the downward short-wave radiation with a range of magnitude from 0 to 1 , representing the reflectance ability of the surface to the solar short-wave radiation. The reflectivity is mainly related to the physical properties of the underlying surface, such as soil color, solar altitude Angle, roughness and soil moisture, etc. [19], and is also related to topography. Generally speaking, the changes of soil roughness and soil color within a day can be regarded as constant. Therefore, in clear days, only the influence of the sun altitude Angle is considered, and the reflectivity is smooth $\mathrm{U}$-shaped.

Figure 3(a) shows the average diurnal variation of reflectance in winter and summer in Naqu region in 2012. It can be seen that the diurnal variation of reflectance in this region presents an asymmetric $U$-shaped change, with significant diurnal variation. The reflectance reaches the maximum after sunrise in the morning, the minimum at noon, and gradually increases in the evening. In the early morning, in addition to the influence of the sun altitude Angle, the dew on the ground plants increases the reflectivity [20]. However, in the evening, the dew does not generally form, so the increase of the reflectivity in the late afternoon is not obvious [21] [22]. The maximum albedo in summer is 0.48 , and that in winter is 0.66 . The albedo in winter is higher than that in summer at all times of the day. This is because of the unique surface features of the plateau region. In 2012 , the average daily reflectance was 0.26 in summer and 0.47 in winter. The

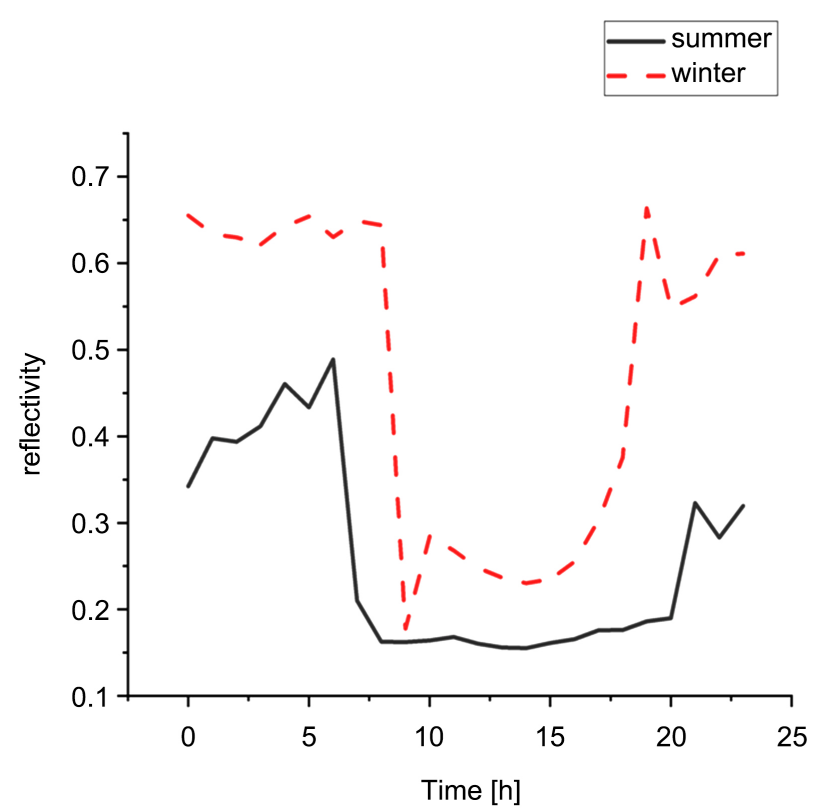

(a)

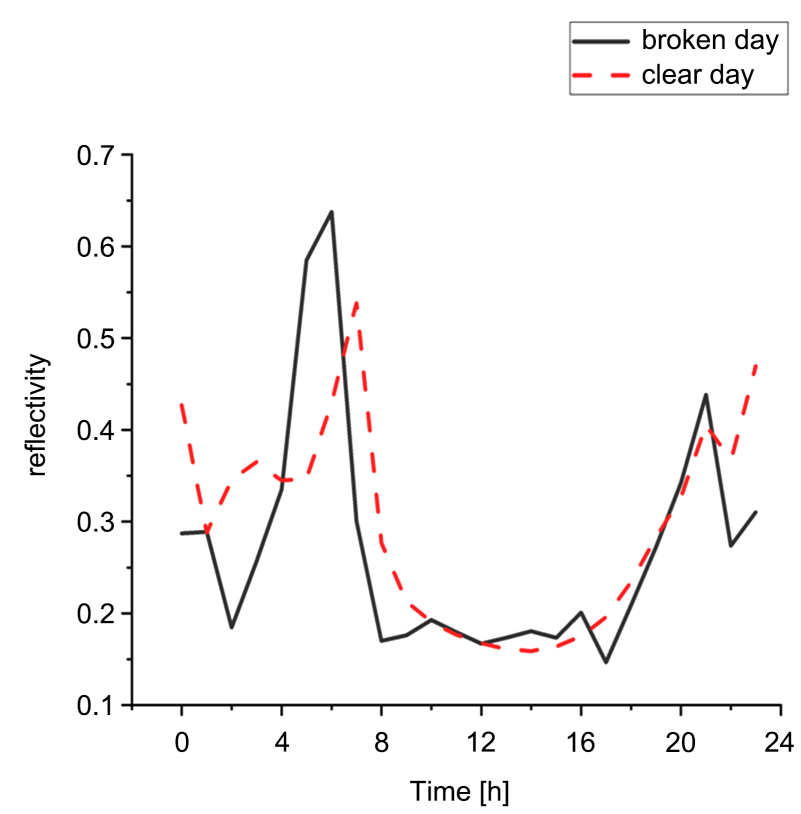

(b)

Figure 3. Diurnal variation of winter and summer reflectance in Naqu area in 2012. (a) Mean diurnal variation in winter and summer reflectivity; (b) average diurnal variation of reflectivity under different weather conditions. 
summer reflectance of this year was higher than the average summer reflectance of Naqu region of 0.19 [23]. It is speculated that the reason is that the scattered radiation from all directions increased in July 2012 due to rainy weather and heavy cloud cover, leading to the increase of surface reflectance. Figure 3(b) shows the diurnal variations of surface reflectance under different typical weather conditions in summer. On cloudy days, the maximum reflectivity is 0.81 , which is slightly smaller than the maximum reflectivity of 0.89 on sunny days. The maximum reflectivity occurs at 7:00 am. According to the research of Fujimaki et al. [24], the surface albedo decreases with the increase of soil moisture within a certain critical value, which is about $0.15 \mathrm{~cm}^{3} / \mathrm{cm}^{3}-0.4 \mathrm{~cm}^{3} / \mathrm{cm}^{3}$.

\subsection{Analysis of Surface Energy Budget in Winter and Summer}

As shown in Figure 4(a) and Figure 4(b) shown in Naqu area of daily variation of surface energy of the components in the winter and summer, sensible heat flux is refers to the turbulent atmosphere with the underlying surface in the form of heat exchange, said when the sensible heat flux is coincided with the ground have surplus energy, negative indicates the transmission of heat into the atmosphere, surface surface energy loss, and sensible heat at night are generally negative. Both the sensible heat flux and latent heat flux in summer and winter have the same diurnal variation trend as the net radiation. In winter, the peak value of sensible heat flux is $89.32 \mathrm{~W} / \mathrm{m}^{2}$ and the average value is $16.59 \mathrm{~W} / \mathrm{m}^{2}$. In summer, the sensible heat flux is significantly larger than that in winter, the peak value is $166.32 \mathrm{~W} / \mathrm{m}^{2}$ and the average value is $38.18 \mathrm{~W} / \mathrm{m}^{2}$. The peak value of latent heat flux in winter is $12.51 \mathrm{~W} / \mathrm{m}^{2}$, and the mean value is $3.5 \mathrm{~W} / \mathrm{m}^{2}$; the peak value in summer is $513.43 \mathrm{~W} / \mathrm{m}^{2}$, and the mean value is $144.52 \mathrm{~W} / \mathrm{m}^{2}$. In winter, the latent heat flux of sensible heat at night has little difference, but in the daytime, the sensible heat flux is significantly larger than the latent heat flux, indicating that the consumption of surface energy in the daytime of winter is mainly dependent on the ground-air sensible heat exchange. In summer, sensible heat flux and latent heat flux are all positive throughout the day, and the surface is receiving heat all the time. Different from winter, sensible heat flux and latent heat flux all play an important role in this process. The sensible heat flux and latent heat flux in summer are significantly higher than those in winter, but the variation of latent heat flux with season is more significant. The reason for this phenomenon is that although the solar radiation is obviously strengthened in summer, there is more precipitation in summer, which inhibits the heat exchange between the atmosphere and the underlying surface. In summer, water vapor activity is strong and convective activity is frequent, so latent heat flux increases significantly in summer. The average daily integral value of net radiation in July was $51.96 \mathrm{MJ} /\left(\mathrm{m}^{2} \cdot \mathrm{d}\right)$ in summer and $5.84 \mathrm{MJ} /\left(\mathrm{m}^{2} \cdot \mathrm{d}\right)$ in winter. In summer, there is a surplus of surface energy, and in winter, although the solar radiation is weakened, there is still a small surplus of energy due to the thermal insulation of the atmosphere. 


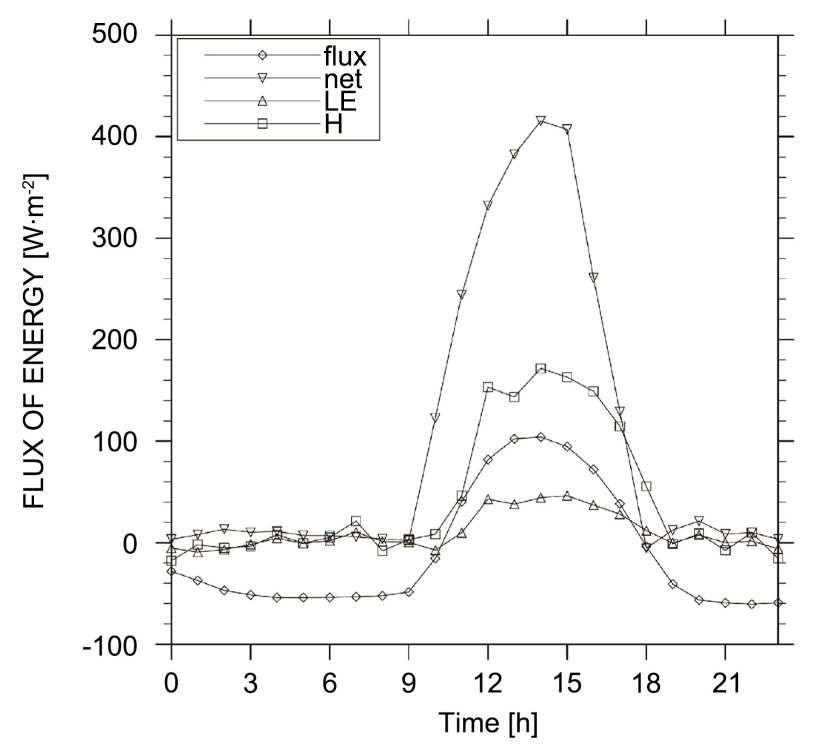

(a)

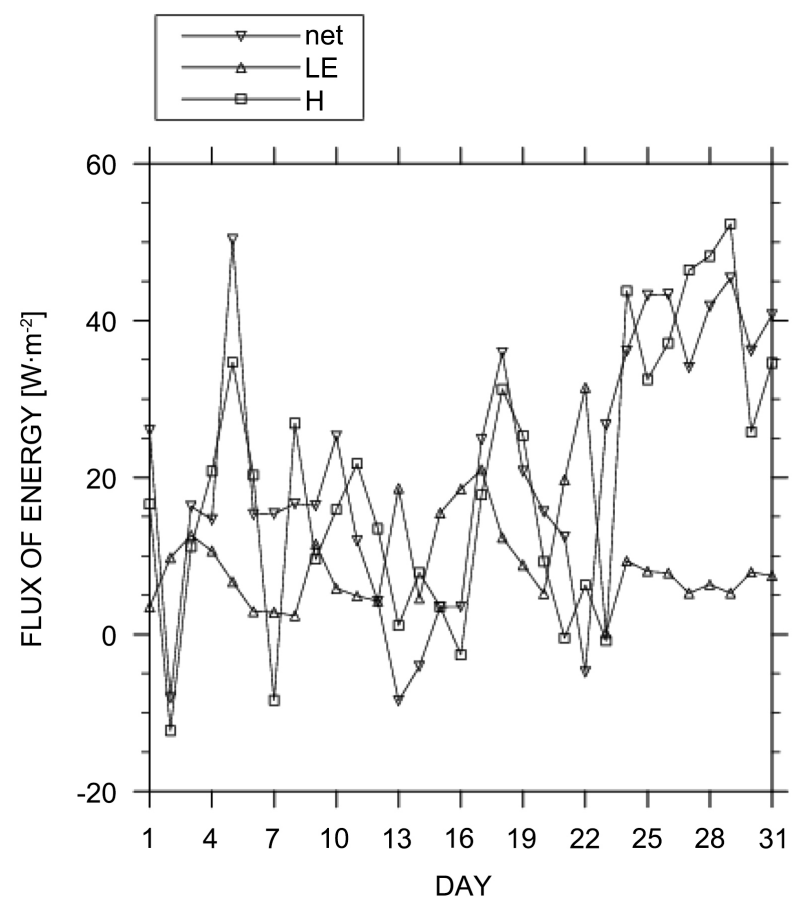

(c)

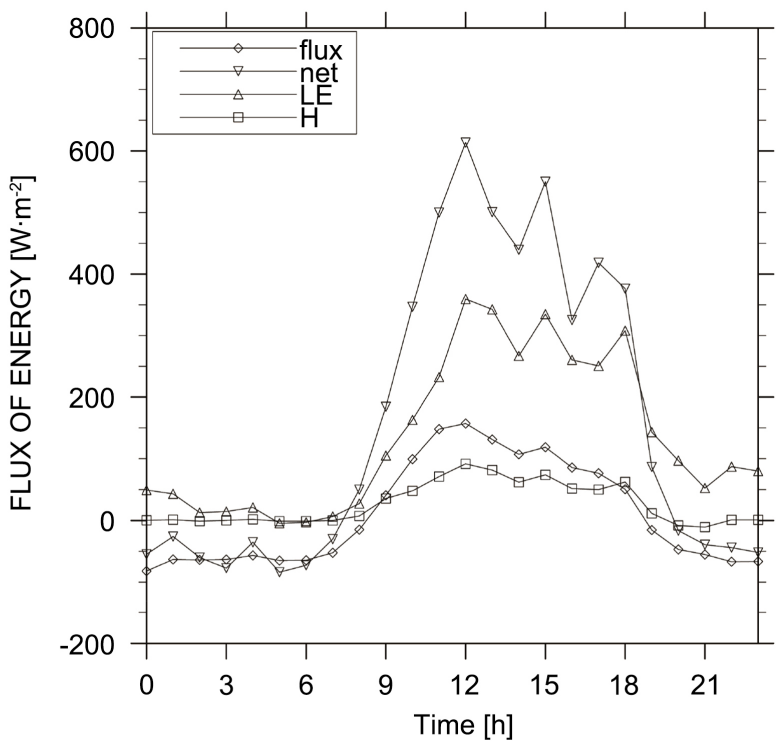

(b)

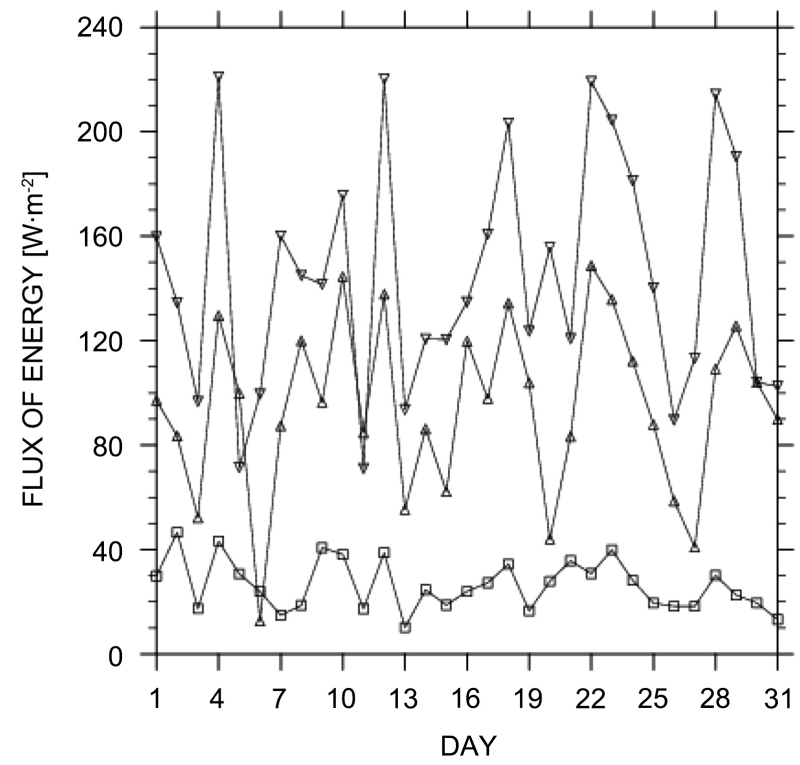

(d)

Figure 4. Variation characteristics of surface energy components in Naqu area in 2012. (a) Average diurnal variation of surface energy components in January; (b) average diurnal variation of surface energy components in July; (c) the surface energy components varied daily in January; (d) the surface energy components varied daily in July.

As a part of the surface energy balance, the surface soil heat flux plays an important role in the energy distribution and cycle, but the surface heat flux cannot be measured directly, but can only be calculated by the method. At present, there are many methods to calculate the surface soil heat flux. Here, we choose the temperature prediction correction method invented by Yang Kun [25] et al.

$$
G=G_{0}+S_{S} .
$$


That is, the surface heat flux $G$ is equal to the sum of the soil heat flux at $5 \mathrm{~cm}$ and the soil heat storage term. Soil heat storage term can be calculated by the following formula:

$$
S_{s}=C_{S} \int_{d}^{0} \frac{\partial T}{\partial t} \mathrm{~d} z
$$

where $d$ is the buried depth of the soil heat flux plate, where is $5 \mathrm{~cm}, C_{s}$ is the soil volume heat capacity, and $T$ is the soil temperature. $C_{s}$ can be calculated according to the following formula:

$$
C_{s}=(1-\eta) \rho_{d} C_{d}+\eta_{w} \rho_{w} C_{w} .
$$

where $(1-\eta) \rho_{d} C_{d}$ was the volume heat capacity of dry soil. Referring to the reference [25], it was found that the value was $0.9 \times 10^{6} \mathrm{~J} /\left(\mathrm{m}^{3} \cdot \mathrm{K}\right), \eta_{w}$ was the soil moisture at $5 \mathrm{~cm}, \rho_{w}$ was the liquid water density $\left(1.0 \times 10^{3} \mathrm{~kg} / \mathrm{m}^{3}\right), C_{w}$ is the specific volume of water $\left(4.18 \times 10^{3} \mathrm{~J} /(\mathrm{kg} \cdot \mathrm{K})\right)$.

In summer, the surface heat flux is negative between 8 o'clock at night and 9 o'clock in the morning, indicating the surface heat loss at night, while in winter, the surface soil heat flux is positive only between 11 o'clock in the morning and 18 o'clock in the afternoon. The daily integral of surface soil heat flux is 2.85 $\mathrm{MJ} / \mathrm{m}^{2}$ in summer and $-2.79 \mathrm{MJ} / \mathrm{m}^{2}$ in winter, so there is a surplus of surface energy in summer, and the surplus in summer will supplement the loss in winter.

\subsection{Energy Closure Analysis}

In the ideal case, the surface energy balance can be expressed as: $R_{n}=H+L e+G$, where $R_{n}$ is the net surface radiation flux, $H$ is the sensible heat flux, $L e$ is the latent heat flux, and $G$ is the surface soil heat flux. However, the surface heat flux cannot be directly observed by instruments at present, so it must be calculated. $G_{0}$ is the soil heat flux of $5 \mathrm{~cm}$ on the surface, $S_{S}$ is the soil heat storage term, and $X$ is the error caused by observation instruments and calculation. Therefore, the more convenient and accurate calculation formula in practical application is as follows:

$$
R_{n}=H+L E+G_{0}+S_{S}+X
$$

Only considering the influence of the soil heat storage term on the closure, the following results are obtained by using the above calculation method:

Table 1 shows the influence of soil heat storage term on energy closure in winter and summer. When the soil heat storage term is considered, the energy closure is 0.296 in summer and 0.607 in winter. The energy closure in winter is significantly higher than that in summer. The reason is that vegetation grows more vigorously in summer, and a considerable part of energy is stored by vegetation. After considering the heat storage term, the energy closure is improved in August and December, $4 \%$ in August and 2\% in winter, and the fitting effect is improved to some extent. This indicates that the heat storage term can not be neglected in the study of surface energy balance. Literature review shows that [15] for grassland at different altitudes, the importance of soil heat storage term in the process of energy balance is different, and more research is needed in this aspect. 
Table 1. Effect of soil thermal storage on energy closure.

\begin{tabular}{cccccc}
\hline \multicolumn{3}{c}{ Consider soil heat storage } & & \multicolumn{2}{c}{$\begin{array}{c}\text { No consideration is given } \\
\text { to soil heat storage }\end{array}$} \\
\cline { 1 - 1 } \cline { 5 - 6 } month & The slope & intercept & & The slope & intercept \\
\hline August & 0.296 & 2.29 & & 0.284 & 3.89 \\
December & 0.607 & 8.09 & 0.592 & 8.93 \\
\hline
\end{tabular}

\section{Conclusion}

\subsection{Main Conclusions}

1) Under cloudy weather, the diurnal variation of surface energy components in Naqu is quite irregular. In cloudy weather, the reflectivity of cloudy weather increases due to the increased scattering from all directions. The daily integral value of downward short-wave radiation and daily radiation in clear days was $96.4 \mathrm{MJ} /\left(\mathrm{m}^{2} \cdot \mathrm{d}\right)$, and the daily integral value of net radiation was $47.04\left(\mathrm{~m}^{2} \cdot \mathrm{d}\right)$, accounting for $48 \%$ of the total daily integral value of radiation. The daily integral value of downward shortwave radiation in cloudy weather is $56.88 \mathrm{MJ} /\left(\mathrm{m}^{2} \cdot \mathrm{d}\right)$, and the daily integral value of net radiation is $24.65 \mathrm{MJ} /\left(\mathrm{m}^{2} \cdot \mathrm{d}\right)$, accounting for $43 \%$. With the increase of cloud cover, the daily integral value of net radiation decreases, and its proportion in the total radiation also decreases, indicating that the variation of thermal process between the surface, atmosphere and deep soil is more intense than that of shortwave radiation under cloudy weather.

2) The downward atmospheric long-wave radiation accounted for $83 \%$ of the upward long-wave radiation of the ground in summer, respectively, while only accounted for $70 \%$ in winter, indicating that the upward long-wave radiation of the ground was "reflected" more by the atmosphere in summer. The reason for this phenomenon is that there are more clouds and rain in summer, and the atmospheric insulation effect is better. The daily integral amounts of upward shortwave radiation in July and December accounted for 16\% and 37\% of downward shortwave radiation, respectively. It was obvious that the reflectance of the underlying surface in Naqu region in winter was higher than that in summer.

3) The average daily reflectance in Naqu region was 0.26 in summer and 0.47 in winter, and the albedo at every moment in winter was higher than that in summer. This is because of the unique surface features of the plateau region. In December and January, the surface is generally covered by snow and ice, and the sun altitude Angle is small at this time, so the winter reflectance is bright.

4) Both the sensible heat flux and latent heat flux in summer and winter have the same diurnal variation trend as the net radiation. The peak value of sensible heat flux in winter is $89.32 \mathrm{~W} / \mathrm{m}^{2}$, and the summer sensible heat flux is significantly larger than that in winter, with a peak value of $166.32 \mathrm{~W} / \mathrm{m}^{2}$. The peak value of latent heat flux in winter is $12.51 \mathrm{~W} / \mathrm{m}^{2}$, and the summer peak value is $513.43 \mathrm{~W} / \mathrm{m}^{2}$. The sensible heat flux and latent heat flux in summer are significantly higher than those in winter, but the variation of latent heat flux with sea- 
son is more significant.

5) When the soil heat storage term is considered, the energy closure is 0.301 in summer and 0.701 in winter. The energy closure in winter is significantly higher than that in summer. The reason is that vegetation grows more vigorously in summer, and a considerable part of energy is stored by vegetation. After considering the heat storage term, the energy closure is improved in August and December, $4 \%$ in August and $2 \%$ in winter, and the fitting effect is improved to some extent. This indicates that the heat storage term can not be neglected in the study of surface energy balance.

\subsection{Discussion}

At present, there are very few stations that carry out long-term continuous observation on the energy exchange of the ground-atmosphere system over the Qinghai-Tibet Plateau in China, and there are few studies on the energy balance of the Plateau lakes and the Plateau inland. The main innovation of this paper is to study this area and analyze the influence of clouds on the surface energy budget in this area. But there are also many shortcomings.

1) For energy imbalance problem, this paper proves that only the shallow soil thermal storage capacity has a certain contribution to the energy balance, but for other factors, such as air and ignore the storage of photosynthesis process, at the same time because of a shortage of the precision of land surface observation instruments, the existence of the intermittent turbulence in the night, making large imbalances still exist. In the future research, further research will be carried out and solutions will be given as far as possible.

2) The study on the hydrological process in this region is relatively scarce in this paper. In the future, the study on the spatial and temporal distribution of soil moisture will be strengthened to explore its influence on the land-air interaction. At the same time, the enhancement effect of vegetation on turbulence and transpiration process of vegetation are not considered too much, which makes the analysis incomplete and will be corrected in the follow-up study.

3) In the study of surface flux, there is still room for improvement in the calculation of surface heat flux. In the future, when the observation data are accurate enough, a more accurate calculation model will be adopted to carry out more rigorous calculations.

\section{Acknowledgements}

Thanks to the National Qinghai-Tibet Plateau Data Center and the Naqu Alpine Climate and Environment Observation and Research Station, Northwest Institute of Eco-Environment and Resources, Chinese Academy of Sciences, for providing the research materials.

\section{Conflicts of Interest}

The authors declare no conflicts of interest. 


\section{References}

[1] Zhang, Q. and Wang, S. (2008) A Study on Land Surface Processes and Their Observational Experiments on the Loess Plateau. Advances in Earth Sciences, No. 2, 167-173.

[2] Qin, D.H. (2005) Assessment of Climate and Environmental Change in China (I): Climate and Environmental Change and Future Trends in China. Climate Change Research Progress, No. 1, 4-9.

[3] Li, S.X., Nan, Z.T. and Zhao, L. (2002) Effects of Freezing-Thawing on the Energy Exchange in the Earth-Atmosphere System. Journal of Glaciology and Geocryology, No. 5, 506-511.

[4] Li, S.X. and Wu, T.H. (2005) Relationship between Earth and Air Temperature in Qinghai-Tibet Plateau. Glaciology and Geocryology, No. 5, 627-632.

[5] Ba, S., et al. (2012) Variation Trend Analysis of Snow Cover in Tibet Based on Multi-Source Data. Glaciology and Geocryology, 34, 1023-1030.

[6] Kumar, et al. (2010) Impact of Surface Flux Formulations and Geostrophic Forcing on Large Eddy Simulations of Diurnal Atmospheric Boundary Layer Flow. Journal of Applied Meteorology and Climatology, 49, 1496-1516. https://doi.org/10.1175/2010JAMC2145.1

[7] Halldin, S., et al. (1998) NOPEX-A Northern Hemisphere Climate Processes Land Surface Experiment. Journal of Hydrology, 212-213, 172-187. https://doi.org/10.1016/S0022-1694(98)00208-X

[8] Wang, J.M. (1999) Experiments on Land Surface Processes and Earth-Atmosphere Interaction: From Heife to Imgrass and Gametibet/Tipex. Plateau Meteorology, No. 3, 280-294.

[9] Lv, D.R. (2005) A Comprehensive Study of Soil-Vegetation-Atmosphere Interaction in Semi-Arid Stepe of Inner Mongolia, China. Acta Meteorologica Sinica, No. 5, 571-593.

[10] Huang, R.H., Zhou, D.G., Chen, W., et al. (2013) Recent Progress in Studies of Air-Land Interaction over the Arid Area of Northwest China and Its Impact on Climate. Chinese Journal of Atmospheric Sciences, 37, 189-210. (In Chinese)

[11] Zhao, P., Xu, X., Chen, F., et al. (2018) The Third Atmospheric Scientific Experiment for Understanding the Earth-Atmosphere Coupled System over the Tibetan Plateau and Its Effects. Bulletin of the American Meteorological Society, 99, 757-776. https://doi.org/10.1175/BAMS-D-16-0050.1

[12] Chen, W., Zhu, D., Liu, H., et al. (2009) Land-Air Interaction over Arid/Semi-Arid Areas in China and Its Impact on the East Asian Summer Monsoon. Part I: Calibration of the Land Surface Model (BATS) Using Multicriteria Methods. Advances in Atmospheric Sciences, 26, Article No. 1088. https://doi.org/10.1007/s00376-009-8187-3

[13] Liu, H.Z. (2006) Diurnal and Seasonal Variations of Water Vapor and Carbon Dioxide Fluxes at the Ground-Air Interface in Semiarid Regions. Atmospheric Sciences, No. 1, 108-118.

[14] Zhang, Q. and Cao, X.Y. (2003) A Study on the Surface Heat and Radiation Balance Characteristics of Desert Gobi in Dunhuang Area. Chinese Journal of Atmospheric Sciences, No. 2, 245-254.

[15] Qiao, J., Zhang, Q. and Zhang, J. (2008) Research Progress on the Parameterization of Land Surface Processes over Heterogeneous Overland Surfaces. Arid Meteorolo$g y$, No. 1, 73-77+88. 
[16] Sen, L. and Zhong, Z. (2013) Improvement of Surface Flux Calculation: A Study Based on Measurements over Alpine Meadow in the Eastern Tibet Plateau in Summer. Chinese Physics B, 23, 029201. https://doi.org/10.1088/1674-1056/23/2/029201

[17] Wen, X.H. (2011) Simulation of Radiation Budget of Jinta Oasis-Gobi by WRF Model. Journal of Solar Energy, 32, 346-353.

[18] Xie, Y. (2019) A Preliminary Analysis of Near-Surface Radiation Budget of Alpine Wetland in the Source Region of the Yellow River. Journal of Solar Energy, 40, 1-10.

[19] Zuo, D.K. (1965) Radiation Balance of the Earth-Atmosphere System and the Atmosphere in East Asia. Acta Geographica Sinica, No. 2, 100-112.

[20] Li, H., Li, Y. and Li, H. (2012) Study on Land Surface Energy Imbalance and Land Surface Process Parameterization in the Semi-Arid Loess Plateau, China. Lanzhou University, Lanzhou.

[21] Zhang, Q., Wang, S. and Wei, G.A. (2003) Study on the Land Surface Physical Parameters of the Gobi Area in Northwest China. Journal of Geophysics, No. 5, 616-623.

[22] Wen, L.J. (2009) Asymmetric Observation of Surface Albedo in Arid Oasis. Solar Energy Journal, 30, 9533.

[23] Qu, D., Ma, W.Q. and Zhaxi, D.Z. (2015) Comparison of Surface Albedo and MODIS Retrieval in Naqu Area, Northern Tibet. Remote Sensing Technology and Application, 30, 908-916.

[24] Fujimaki, H., Shiozawa, S. and Inoue, M. (2003) Effect of Salty Crust on Soil Albedo. Agricultural and Forest Meteorology, 118, 125-135. https://doi.org/10.1016/S0168-1923(03)00110-2

[25] Yang, K. and Wang, J.M. (2008) A Temperature Forecasting Correction Method for Calculating Surface Soil Heat Flux Based on Soil Temperature and Moisture Data. Science in China (Series D: Earth Sciences), No. 2, 243-250. 